\title{
PENERAPAN PLAY THERAPY UNTUK MENINGKATKAN PERILAKU BERSEKOLAH PADA ANAK DENGAN SCHOOL REFUSAL BEHAVIOR (SRB)
}

\section{ESTY ARYANI SAFITHRY}

\author{
Dosen Program Studi Bimbingan dan Konseling Fakultas Keguruan dan IImu Pendidikan \\ Universitas Muhammadiyah Palangkaraya \\ Email : estyesty07@yahoo.com
}

\begin{abstract}
This research aims to determine whether play therapy can improve the behavior of school children with school refusal behavior. This research used single case study. The subjects used in this research amounts to one person who has school refusal behavior. Methods of data collection using interviews, observation and documentation. Stages ofis divided into10 sessions of therapy sessions plus pretreatment, post-treatment and follow-up.

Results of this research showed improvement in school behavior at the time pre treatment only 1 time a week to 6 times on a follow-up session.
\end{abstract}

Keywords: play therapy, school refusal behavior

\begin{abstract}
ABSTRAK
Penelitian ini bertujuan untuk mengetahui apakah play therapy dapat meningkatkan perilaku bersekolah pada anak dengan school refusal behaviour. Penelitian menggunakan jenis penelitian studi kasus tunggal. Subjek yang digunakan dalam penelitian ini berjumlah 1 orang yang memiliki perilaku school refusal. Metode pengumpulan data menggunakan wawancara, observasi dan dokumentasi. Tahap terapi dibagi menjadi 10 sesi ditambah sesi praterapi, pasca terapi dan follow up. Hasil penelitian ini menunjukan ada peningkatan perilaku bersekolah yang pada saat praterapi hanya 1 kali dalam seminggu menjadi 6 kali pada sesi follow up.
\end{abstract}

Kata kunci : play therapy, school refusal behavior

\section{PENDAHULUAN}

Sekolah pada masa kini, telah menjadi lingkungan esensial yang tidak dapat dipisahkan dari kehidupan anak karena sebagian besar waktu anak dihabiskan untuk beraktivitas di tempat tersebut. Akan tetapi terdapat beberapa anak yang tidak dapat menikmati aktivitas bersekolah karena memendam rasa takut yang berlebihan (Beidel \& Turner, 2005). Rasa takut tersebut mungkin disebabkan oleh peristiwa kurang menyenangkan yang terkait dengan guru, teman, pelajaran, atau bahkan masalah dengan keluarga, yang membuat anak merasa tidak nyaman untuk bersekolah. Sayangnya tidak semua anak mampu mengungkapkan masalahnya kepada orang lain dan cenderung memendam ketakutannya sendiri (Wenar \& Kerig, 2005). Hal itu membuat mereka tidak memperoleh bantuan untuk menyelesaikan masalahnya walaupun di sisi lain mereka juga sulit menemukan cara untuk mengatasi ketakutannya. Tak jarang anak akhirnya menolak pergi ke sekolah untuk menghindari hal yang ia takuti. 
Berdasarkan hasil wawancara awal dengan orang tua bahwa subjek RP sebenarnya masih berusia 5 tahun dimana pada usia itu seharusnya RP masih duduk di bangku TK, namun karena sejak nol kecil RP sudah bisa membaca dan berhitung, gurunya menyerankan agar RP langsung dimasukan ke SD saja dan orangtuanya pun setuju. la memang terlihat lebih kecil dari anak seusianya namun berbadan gemuk.

la tidak menunjukan permasalahan pada saat masih TK dan awal-awal masuk SD. Namun setelah libur semester 1 subjek mulai malas masuk sekolah, biasanya terjadi pada hari senin. Setiap pagi khususnya pada hari senin RP mengatakan bahwa ia tidak mau sekolah, jika ditanya kenapa ia tdak mau masuk sekolah biasanya jawabanya adalah ia sakit kaki kalau pakai sepatu, takut dimarahi ibu guru, tidak suka sekolah itu, dan lain-lain. Biasanya pergi ke sekolah sambil menangis, menempel terus dengan orang tua menunjukkan sikap rewel. Kejadian ini telah berlangsung sekitar 2 bulan. Tentu perilakunya ini sangat mengganggu aktifitas dimana kedua orangtuanya harus bekerja dan kakanya juga sekolah. Biasanya kalau RP sudah menangis, orangtuanya akan mengatakan bahwa ia tidak boleh main PS lagi kalau tidak mau berangkat sekolah dan akhirnya ia mau juga berangkat sekolah. Tetapi hal tersebut selalu berulang pada minggu berikutnya, dimulai pada hari senin. Biasanya ia mengalami School Refusal ini sekitar 3-5 kali dalam seminggu. Walaupun sudah dibujuk, dirayu, dan diiming-imingi dengan hadiah yang menarik, dia tetap tidak mau sekolah.

Permasalahan yang dihadapi oleh orang tua subjek diatas dapat diambil kesimpulan bahwa subjek mengalami School Refusal yaitu kejadian dimana seorang anak mengalami keengganan untuk datang ke sekolah karena suatu sebab. School Refusal ini kasus yang masih ringan dibandingkan dengan fobia sekolah. Fobia sekolah/School Phobia biasanya lebih sering disertai dengan gejala fisik misalnya tiba-tiba sakit kepala, muntah, sakit perut dan perasaan tegang, takut yang berlebihan ketika akan masuk sekolah. School Refusal yang kurang ditangani dengan baik biasanya akan berkembang menjadi fobia sekolah.

Penelitian yang diterbitkan pada Journal of Behavior Therapy \& Experimental Psychiatry (2006) Terapi bermain adalah proses terapi khusus yang berfokus pada kebutuhan anak untuk mengekspresikan diri melalui penggunaan permainan dan mainan. Anak-anak didorong untuk bermain sebagaimana biasanya dan terapis akan menyediakan lingkungan yang aman serta memberi arahan. Dalam proses ini, proses bermain anak-anak untuk diarahkan mendorong ekspresi emosional mereka. Anak-anak diberi kesempatan untuk mengekspresikan diri melalui berbagai gaya termasuk bermain seni, bermain pasir, bermain drama dan bermain fantasi.

Tujuan yang ingin dicapai dari penelitian ini adalah untuk mengetahui apakah play therapy dapat meningkatkan perilaku sekolah pada anak dengan school refusal behaviour dan mengetahui perilaku positif apa yang muncul setelah diberikan play therapy.

\section{METODOLOGI Rancangan Penelitian}

Dalam penelitian ini peneliti menggunakan jenis penelitian studi kasus tunggal yang merupakan sebuah desain penelitian untuk 
mengevaluasi efek suatu perlakuan dengan kasus tunggal. Elemen desain yang digunakan dalam penelitian ini adalah $A B A$ design, di mana $\mathrm{A}$ adalah fase sebelum terapi, $B$ adalah fase terapi atau intervensi yang kemudian dilanjutkan dengan fase tindak lanjut A (Kazdin, 2005).

\section{Subjek Penelitian}

Subjek yang digunakan dalam penelitian ini berjumlah 1 orang yang memiliki perilaku school refusal yaitu. Biasanya pergi ke sekolah sambil menangis, menempel terus dengan orang tua menunjukkan sikap rewel. Kejadian ini telah berlangsung sekitar 2 bulan.

\section{Metode Pengumpulan Data}

Wawancara dilakukan sebagai metode untuk melakukan asesmen pada tahap pra terapi, selama proses terapi, pasca terapi dan tindak lanjut. Observasi dalam penelitian ini bersifat non partisipan yang berarti peneliti tidak terlibat dalam aktivitas yang diamatinya (Poerwandari, 2001). Observasi dilakukan oleh peneliti dan subyek sendiri terhadap tingkah laku yang menjadi fokus terapi.

\section{Prosedur Intervensi}

Tahap intervensi ini berjumlah 14 sesi, terdiri dari 2 sesi praterapi, 10 sesi proses terapi, 1 sesi tahap post terapi dan 1 sesi tahap follow up

\section{Tahap praterapi}

Pada tahap ini kegiatan yang dilaksanakan adalah memberikan informasi atau pengetahuan kepada orang tua mengenai school refusal, penyebab mengapa hal tersebut bisa terjadi serta alternatif-alternatif penyelesaianya. Selain pemberian informasi pada tahap ini, orang tua berkomitmen untuk bekerja sama selama proses terapi agar tujuan terapi dapat tercapai.

\section{Tahap terapi}

Pada tahap ini terdiri dari 9 sesi. Kegiatanya antara lain modelling yang dilakukan oleh orang tua subjek, game play therapy dan roleplay.

\section{Tahap pascaterapi}

Kegiatan paska terapi ini kegiatanya adalah mengidentifikasi perilaku-perilaku positif apa yang telah muncul dan pemberian lembar evaluasi kepada orang tua yang berisi apa saja perubahan yang telah subjek rasakan.

\section{Tahap follow up}

Tahap ini dilakukan untuk melihat apakah hasil dari proses terapi bisa bertahan permanen, meskipun sudah tidak ada lagi penanganan. Tahap ini akan dilakukan 2 minggu setelah proses terapi berakhir.

\section{HASIL DAN PEMBHASAN}

\section{Hasil Terapi}

Proses terapi dilaksanakan pada sesi 1-9. Prosesnya antara lain :

\section{Sesi 1-3}

\section{a. Modeling}

1) Terapis memperagakan sendiri perilaku-perilaku yang harus ditiru anak.

2) Anak memperagakannya persis seperti cerita yang diperagakan terapis.

3) Subjek disuruh menceritakan kembali kenapa spongebob tidak mau masuk sekolah dan subjek menjawab spongebob tidak mau sekolah karena takut diganggu oleh teman-temanya, kemudian patrick membujuknya untuk sekolah karena setelah pulang sekolah 
mereka akan bermain, kalau spongebob tidak mau berangkat sekolah maka patrick akan marah dan tidak mau berteman lagi denganya, kemudian spongebob mau berangkat sekolah.

\section{b. Game Play Therapy}

1) Subjek bermain "the Sims" bersama kakak dan sepupunya.

2) Pada permainan ini kakak subjek yang jadi pemenangnya dan subjek menjadi juara ke dua

3) Kemudian subjek ditanya kenapa ia kalah dan subjek menjawab karena the simsnya terlalu banyak bermain dan tidak mempunyai teman maka ia lupa sekolah dan dikeluarkan dari sekolahan.

c. Role Play

1) Kakak bercerita tentang sesuatu kemudian anak dan sepupunya mendengarkan cerita kakak

2) Anggota yang lain menanggapinya

3) Kemudian adik yang disuruh bercerita tentang pengalaman yang menyenangkan dan kakak serta sepupunya menanggapi cerita subjek.

\section{d. Behavioral}

Dilakukan setiap anak menunjukan perilaku yang baik, misal saat subjek mendapatkan nilai yang bagus, orang tua mengatakan bahwa ia adalah anak yang paling pintar di kelasnya.

\section{Sesi 4-5}

\section{a. CBPT dengan Modeling}

1) Dengan menggunakan lebih banyak boneka. Terapis bercerita "Mari kita bermain binatang-binatang ini yang mau pergi ke sekolah" jadi dengan binatang-binatang itu terapis menggambarkan situasi sekolah.

2) Ada binatang yang berperan sebagai dia dan temannya, ada binatang yang berperan sebagai gurunya, ternyata anak menceritakan bahwa "Guru ini suka memarahi dan teman-temanya suka mengambil bekal makanannya" barulah dia bercerita kalau dia dimarahi oleh gurunya dan diejek oleh temanya.

b. Game Play Therapy

Kali ini subjek masih tetap menjadi juara dua namun ia sudah mendapatkan teman yang lebih banyak dan ia adpat menceritakan bahwa dengan mempunyai teman yang banyak maka ia akan mendapatkan nilai yang bagus dan menajadi juara kelas.

c. Role Play

Masing-masing anak bercerita dan yang lain menanggapi cerita tersebut.

d. Behavioral

Dilakukan setiap anak menunjukan perilaku yang baik, misal saat subjek mendapatkan nilai yang bagus, orang tua mengatakan bahwa ia adalah anak yang paling pintar dikelasnya.

\section{Sesi 6-7}

\section{a. CBPT dengan Modeling}

1) anak dibebaskan bercerita tentang apa saja tetapi temanya adalah tentang anak yang tidak mau sekolah menceritakan situasi yang ada 
disekolahnya dan bagaimana cara menyelesaikanya

2) Kemudian anak bercerita bahwa anak yang tidak mau sekolah akan dikeluarkan dari sekolah dan yang mau sekolah akan mendapatkan nilai yang bagus

b. Game Play Therapy

1) Subjek beserta kakak dan sepupunya memperagakan permainan "the sims" tersebut sesuai dengan kararkter yang mereka mainkan.

2) Misal subjek berpura-pura mandi, makan sebelum berangkat sekolah dan mencari banyak teman serta belajar agar mendapatkan nilai yang bagus dan naik kelas (lebih kepada metode role playing).

c. Role Play masing-masing anak bercerita dan yang lain menanggapi cerita tersebut.

\section{d. Behavioral}

Dilakukan setiap anak menunjukan perilaku yang baik, misal saat subjek mendapatkan nilai yang bagus, orang tua mengatakan bahwa ia adalah anak yang paling pintar dikelasnya.

\section{Sesi 8-9}

a. CBPT dengan Modeling

1) Anak berganti peran, dimana ia memainkan figur ibu guru yang menasehati muridnya agar mau brangkat kesekolah.

2) la juga memainkan peran orang tua yang mencoba menenangkan anaknya yang sedang menangis. b. Game Play Therapy

1) Subjek ditanyai apa saja yang telah ia pelajari dari bermain "The Sims"

2) la dapat menjelaskan bahwa dengan mempunyai banyak teman ia dapat menjadi murid yang paling pintar di kelasnya

c. Role Play

Masing-masing anak bercerita dan yang lain menanggapi cerita tersebut.

d. Behavioral

Dilakukan setiap anak menunjukan perilaku yang baik, misal saat subjek mendapatkan nilai yang bagus, orang tua mengatakan bahwa ia adalah anak yang paling pintar dikelasnya.

\section{Pembahasan}

Berdasarkan hasil konseling diatas dapat diambil kesimpulan bahwa subjek mengalami mogok sekolah atau School Refusal, adalah kejadian dimana seorang anak mengalami keengganan untuk datang ke sekolah karena suatu sebab. Mogok sekolah ini kasus yang masih ringan dibandingkan dengan fobia sekolah Fobia sekolah/School Phobia biasanya lebih sering disertai dengan gejala fisik misalnya tiba-tiba sakit kepala, muntah, sakit perut dan perasaan tegang, takut yang berlebihan ketika akan masuk sekolah. Mogok sekolah yang kurang ditangani dengan baik biasanya akan berkembang menjadi fobia sekolah. 
Tabel 1. Kemajuan subjek per sesi

\begin{tabular}{|c|c|c|c|c|c|}
\hline No & Metode & Sesi 1 - 3 & Sesi 4 - 5 & Sesi 6 - 7 & Sesi 8 - 9 \\
\hline 1. & Modelling & $\begin{array}{l}\text { Mampu } \\
\text { memperagakan } \\
\text { figur yang sesuai } \\
\text { dengan yang } \\
\text { dicontohkan terapis }\end{array}$ & $\begin{array}{l}\text { Dapat menjelaskan } \\
\text { kenapa ia tidak mau } \\
\text { beragkat kesekolah }\end{array}$ & $\begin{array}{l}\text { Menyadari bahwa } \\
\text { anak yang tidak } \\
\text { mau sekolah akan } \\
\text { dikeluarkan dari } \\
\text { sekolah dan yang } \\
\text { mau sekolah akan } \\
\text { mendapatkan nilai } \\
\text { yang bagus }\end{array}$ & $\begin{array}{l}\text { Dapat berperan } \\
\text { sebagai guru dan } \\
\text { orang tua yang } \\
\text { anaknya menangis } \\
\text { dan mampu } \\
\text { menasehatinya }\end{array}$ \\
\hline 2. & Game play & $\begin{array}{l}\text { Mengetahui bahwa } \\
\text { tidak punya teman } \\
\text { akan berakibat } \\
\text { dikeluarkan dari } \\
\text { sekolah }\end{array}$ & $\begin{array}{l}\text { Dapat menceritakan } \\
\text { dengan banyak } \\
\text { teman, ia akan } \\
\text { menjadi juara kelas }\end{array}$ & $\begin{array}{l}\text { Dapat memerankan } \\
\text { peranya masing- } \\
\text { masing di game } \\
\text { "the sims" }\end{array}$ & $\begin{array}{l}\text { Dapat menjelaskan } \\
\text { manfaat dari } \\
\text { bermain "The sims" }\end{array}$ \\
\hline 3. & Role play & $\begin{array}{l}\text { Mampu bercerita } \\
\text { dan mampu } \\
\text { memperhatikan } \\
\text { kakaknya }\end{array}$ & $\begin{array}{l}\text { Merasa senang } \\
\text { karena ceritanya } \\
\text { diperhatikan }\end{array}$ & $\begin{array}{l}\text { Mengetahui bahwa } \\
\text { dengan } \\
\text { memperhatikan } \\
\text { teman dan } \\
\text { mendengarkanya } \\
\text { bercerita dapat } \\
\text { membuatnya } \\
\text { senang }\end{array}$ & $\begin{array}{l}\text { Mampu } \\
\text { memperagakanya } \\
\text { di sekolah bersama } \\
\text { teman-teman yang } \\
\text { lain }\end{array}$ \\
\hline 4. & & & & ng sesi) Ana & $2 n$ \\
\hline
\end{tabular}

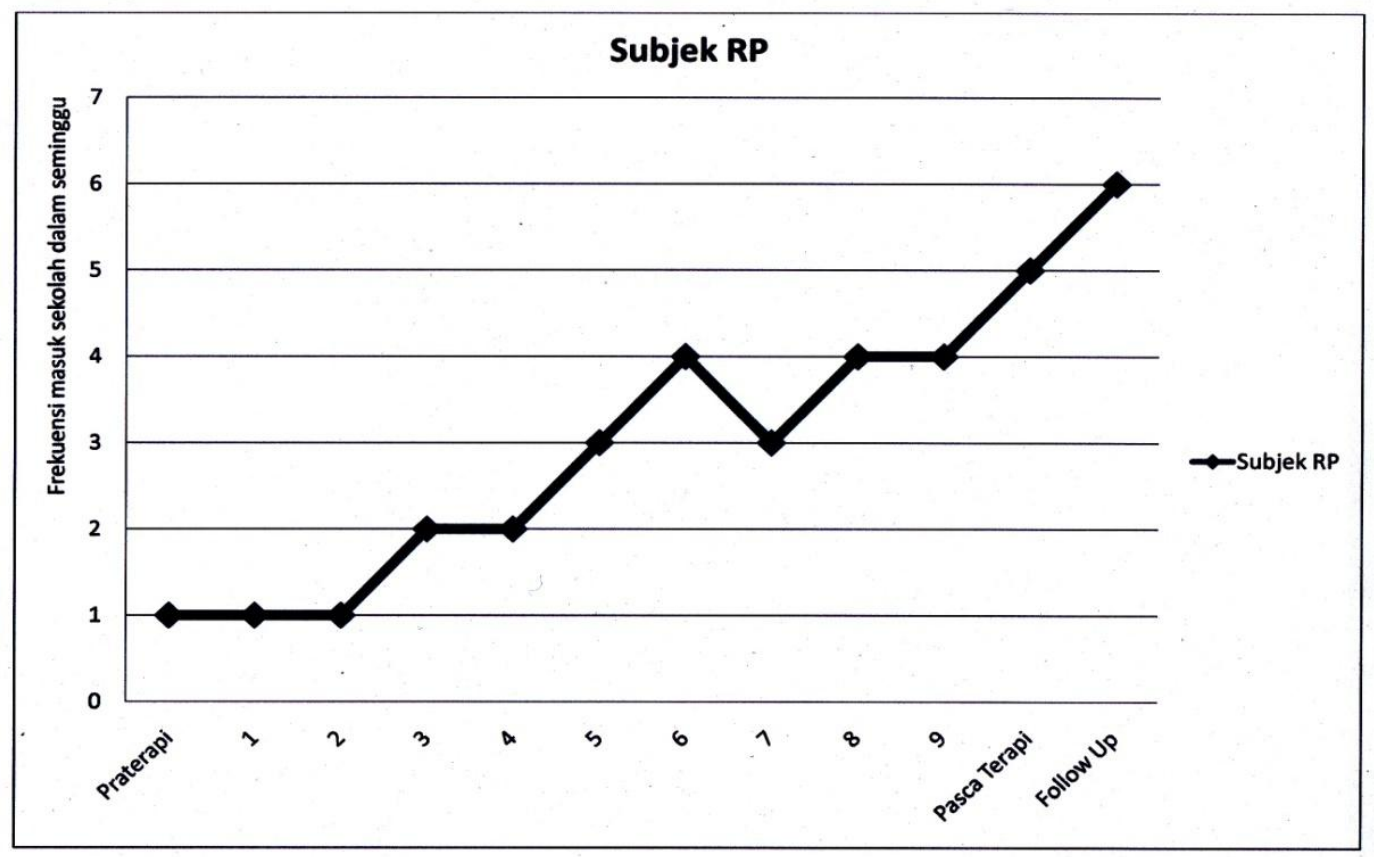

Gambar 1. Grafik penurunan perilaku school refusal dari sesi praterapi sampai follow up 
Penyebab dari kasus penolakan bersekolah dikelompokkan menjadi 3:

\section{a. Faktor dari dalam diri anak}

1. Anak mengalami distress emosional tertentu seperti kecemasan, depresi atau kesulitan berhubungan dengan lingkungan, serta kesulitan belajar.

Pada masalah RP ini, ia mengalami kecemasan akan perpisahan (separation anxiety). Anak dengan kecemasan ini cenderung terikat pada orang tua, jika harus berpisah dengan orang tuanya ia akan menunjukan suatu perilaku tantrum. RP hampir setiap minggu menunjukan perilaku tantrum ini dan ia juga mengatakan bahwa ia takut berada jauh dari orang tuanya dan sangat gelisah jika orangtuanya terlambat menjemputnya.

2. Anak kesulitan dalam menyesuaikan diri Masa kanak-kanak biasa disebut dengan tahap mainan, karena pada tahap ini hampir semua permainan menggunakan mainan (Hurlock, 2000). Di dalam bermain anak memiliki nilai kesempatan untuk mengekspresikan sesuatu yang ia rasakan dan pikirkan. Dengan bermain, anak sebenarnya sedang mempraktekkan keterampilan dan anak mendapatkan kepuasan dalam bermain, yang berarti mengembangkan dirinya sendiri. Dalam bermain, anak dapat mengembangkan otot kasar dan halus, meningkatkan penalaran, dan memahami keberanaan lingkungannya, membentuk daya imajinasi, daya fantasi, dan kreativitas. Jadi jika pada masa bermain anak ini terhambat maka anak akan mengalami stres karena anak belum siap menghadapi situasi-situasi yang serius.

Seperti pada RP, salah satu penyebab kenapa ia tidak mau sekolah dikarenakan ketidaksiapan dia mamasuki bangku SD, dimana ia baru berusia 5 tahun yang seharusnya masih duduk di bangku TK. Situasi di SD yang berbeda dari TK membuat subjek kesulitan dalam menyesuaikan diri, diantaranya tidak ada mainan, teman-temanya yang berbadan lebih besar darinya sering mengganggunya dan guru yang tidak seramah sewaktu ia TK.

b. Faktor yang berasal dari orangtua, terutama berkaitan dengan interaksi anakorangtua

Anak dengan temperamen sulit dan pemalu seringkali memiliki interaksi buruk dengan orangtuanya sehingga memicu kecemasan anak.

Orang tua RP selalu memaksanya untuk belajar. Bahkan jika RP memulai mogok sekolahnya, orang tuanya mengancam bahwa ia tidak boleh bermain jika ia tidak mau berangkat kesekolah. Akhirnya anak mau berangkat kesekolah namun dengan perasaan cemas. RP kesulitan dalam mengkomunikasikan perasaannya kepada orang tuanya, jika ditanya ia hanya menjawab bahwa ia malas memakai sepatu atau karena rumahnya yang jauh dari sekolahan

\section{c. Faktor lingkungan sekolah}

Hubungan yang tidak serasi antara anak dengan teman-teman sekolahnya. Dikarenakan usia RP yang lebih muda 
daripada teman-temanya dan ia merasa murid yang paling kecil dikelas. Temantemanya memang sering mengganggunya misal mengambil kotak nasinya dan menertawakanya saat pelajaran olah raga.

Play terapi dilakukan selama 3 kali, setiap sesi dilihat bagaimana perkembangan anak dan memberikan beberapa tugas kepada orang tua yang akan dievaluasi pada sesi berikutnya.

Kemajuan anak pada setiap sesi sangat jelas terlihat, hal ini dikarenakan kemampuan komunikasi dan kerjasama anak yang bagus apalagi didukung dengan hobi anak yang senag bermain maka terget terapi mudah sekali tercapai. Selain kerjasama dengan anak yang bagus, kerjasama orangtua juga berperan penting, dimana orang tua dapat melakukan tugas mereka dengan baik dan sangat mendukung dalam proses play terapi ini. Kendala dari terapi ini adalah tidak dapat mengahadirkan guru dan murid-murid dikelas yagn bersangkutan dikarenakan keterbatasan waktu dan prosedur perijinan serta jadual sekolah yang sudah mendekati ujian. Namun hal tersebut tidak terlalu berpengaruh kepada keberhasil play terapi.

\section{KESIMPULAN DAN SARAN}

\section{Kesimpulan}

1. Dari hasil play therapy ada kemajuan yang ditunjukan subjek, dari yang hanya masuk sekolah tanpa menangis 1 kali seminggu pada tahap praterapi menjadi 6 kali masuk sekolah tanpa menangis dalam satu minggu. pada sesi terakhir subjek dapat masuk sekolah satu minggu tanpa menangis.

2. Perilaku positif yang muncul setelah dilaksanakan terapi yaitu subjek mulai menunjukan kepercayaan dirinya di dalam kelas, seperti berani maju ke depan kelas untuk menjawab pertanyaan dari guru dan mampu membangun komunikasi dengan teman-temanya.

\section{Saran}

1. Untuk orang tua memberi pujian pada anak sekecil apapun usaha yang telah dilakukan anak.

2. Untuk guru kelas sebaiknya peka jika ada anak didik yang dibully oleh teman-temanya dan memberikan hukuman yang suai terhadap perilaku yang negatif tersebut.

3. Untuk pihak sekolah agar lebih intens untuk berkomunikasi dengan orang tua, karena permasalahan anak tidak saja terjadi di sekolah tetapi juga di rumah

4. Untuk peneliti selanjutnya sebaiknya penelitian lebih diperluas yaitu menangani masalah bullying agar perilaku school refusal dapat diturunkan

\section{DAFTAR PUSTAKA}

Beidel, D. C. \& Turner, S. M. (2005). Childhood anxiety disorders: $A$ guide to research and treatment. New York: Routledge Taylor \& Francis Group.

Brill, L. D. (2009). "School refusal: Characteristics, assessment, and effective treatment: $A$ child and parent perspective". Disertasi Doktoral Psikologi, Philadelphia College of Osteopathic Medicine.

Chorpita, B. F., Albano, A. M., Heimberg, R. G., \& Barlow, D. H. (2006). "A systematic replication of the prescriptive treatment of school refusal behavior in a single subject". Journal of Behavior Therapy \& Experimental Psychiatry, 27, 3, 281-290 
Crenshaw, S, D \& Brook Robert ( 2013)Play Therapy Interventions to Enhance Resilience USA: Pearson Prentice Hall. Gosschalk, P.O.

Diagnostic And Statistical Manual of Mental Disorders. Fourth Edition (2000). Washington, DC: American Psychiatric Association.

Haarman, G. B. (2009). "School refusal behavior: Effective techniques to help children who can't or won't go to school'.www.heiselandassoc.com/

Hendron, M. C. (2006). "School refusal behavior: the relationship between functions and symptom sets". Tesis pada University of Nevada, Las Vegas.

Hurlock, Elizabeth.(2005). Psikologi Perkembangan. Jakarta : Erlangga

Kazdin, A.E. (2009). Methodological Issues\& Strategies in Clinical Research. Washington DC : American Psychological Association.

Kearney, C. A. \& Albano, A. M. (2007). When children refuse school: $A$ cognitive behavioral therapy approach, $2^{\text {nd }}$ edition.

King, N., Tonge, B. J., Heyne, D., \& Ollendick, T. (2010). "Research on the cognitive-behavioral treatment of school refusal: A review and recommendations." Clinical Psychology Review, 20, 4, 495-507.

Mills, B \& Bard B (2009) Behavioral Treatment of Acute Onset School Refusal in a 5-year old Girl with Separation Anxiety Disorder.Education and Treatment of Children, Vol.27, No.2, 150-160.

Nemiroff, Marc A. Jane Annunziata (2010), A Child's First Book About Play Therapy.Washington, DC: American Psychological Association

Nevid, S, Jeffrey, Ratus, A, Spencer, Greene, Beverly. 2005. Psikologi Abnormal. Erlangga. Jakarta.
Wenar, C. \& Kerig, P. (2005). Developmental Psychopathology: from Infancy through Adolescence 5th ed. New York: McGrawHill

Wilson, Kate \& Kendrick , Paula (2012) Play Therapy: A Non-Directive Approach for Children and Adolescents Tesis pada University of Nevada, Las Vegas.

Witts, B. \& Houlihan, D. (2007)."Recent perspectives concerning school refusal behavior". Journal of Research in Educational Psychology, 5, 12, 381-398. 